\title{
Vaccination Status and Factors Associated With It among Children Aged 12- 23 Months in Wadera District, South East Ethiopia
}

\section{Udessa $\mathbf{G}^{1}$, Sena $\mathrm{L}^{2}$ and Berhanu $\mathrm{S}^{2 *}$}

${ }^{1}$ Department of Guji Zone Health, Guji, Oromia Ethiopia

${ }^{2}$ Department of Epidemiology, Jimma University, Ethiopia

\begin{abstract}
Background: Vaccination is one of public health interventions that protect children from vaccine-preventable diseases. In 2012 the WHO revealed that around 1.5 million children worldwide died from vaccine-preventable diseases. There for the objective of the study was to assess Vaccination status and factors associated with it among children aged 12-23 months in Wadera District.

Methods: A cross-sectional study was conducted from May to June 2016. Stratified simple random sampling technique was used to select study participants and semi-structured questionnaire using interview-administered technique was used to collect data. The collected data were entered using Epi Data version 3.2 and analyzed by SPSS version 20. Multivariate logistic regression with $95 \%$ Confidence Interval $(\mathrm{Cl})$ and $p$ value $<0.05$ level of significance were used to assess factors associated with vaccination status.

Results: Four hundred four mothers were interviewed, giving a response rate of $98.2 \%$ and from the total, $41.4 \%$ were fully vaccinated while $5.9 \%$ of the children were unvaccinated. Variables showing further association includes; had three or above Anti Natal Care (ANC) visit [AOR=3.8 (2.1-6.9)], three or above doses of TT vaccine [AOR=4 (1.79.6)], Children born in health institutions [AOR=2.1 (1.1- 4.0)], had Post Natal Care (PNC) follow up [AOR=2.8 (1.65.0)], mothers who were walked less than $30 \mathrm{~min}$ to Vaccination site [AOR=4.0 (1.2-13.2)] and mothers who had good knowledge on vaccine $[\mathrm{AOR}=5.7(2.9-11.2)]$.
\end{abstract}

Conclusion: The vaccination coverage in the District was low.

Keywords: Vaccination; Fully vaccinated; Children 12-23 month of age; Wadera district

\section{Introduction}

Vaccination is one of the cost-effective and lifesaving public health interventions that can be used to protect children from vaccinepreventable diseases. Vaccine-preventable diseases constitute a major cause of morbidity and mortality in children under-five years of age [1]. The Expanded Programme on Immunization (EPI) was established in 1974 against six vaccine preventable diseases. These are diphtheria, polio, tuberculosis, measles, pertussis and tetanus. Now a day's vaccination continue to increase protecting children against 14 diseases-diphtheria, pertussis, tetanus, measles, polio, tuberculosis, hepatitis B, Hib, rubella, meningococcal disease, pneumococcal disease, rotavirus diarrhea, and (in certain areas) Japanese encephalitis and yellow fever [2]. EPI was launched in Ethiopia in 1980 with the objective of achieving 100\% vaccination coverage of all children under the age of two years by 1990. The national EPI schedule targets children under one year providing BCG vaccine given at birth, three doses of DPT-HepB-Hib and PCV vaccine given at 6,10 and 14 weeks of age, four doses of oral polio vaccine given approximately at $0,6,10$, and 14 weeks of age, two doses of Rota vaccine given at 6 and 10 weeks and measles vaccine given at 9 months of age. Vaccination service delivery strategies include fixed (static), outreach, and mobile sites at government and private health facilities $[3,4]$. As per the updated Ethiopian Immunization Policy of 2007, children under the age of one and women of 15-49 years are the targets for the EPI vaccines. Immunization services in Ethiopia are provided free of charge in most of the health facilities as well as and in the outreach services for communities residing beyond $5 \mathrm{~km}$ from the health facilities [5].

Vaccine Preventable Diseases are responsible for about $25 \%$ of the 10 million deaths occurring annually among under five years children.
Vaccines were widely regarded as an effective but across the world 26.3 million children below the age of one year had not been vaccinated with DPT3 in 2008 [6]. The progress in low and middle income countries (LMIC) in vaccination coverage is slow nevertheless and DPT3 coverage in sub-Saharan Africa is estimated to be $60 \%$. Among the estimated 27 million children that were yet to be reached with DPT3 vaccine, 9.9 million were in South Asia and 9.6 million in sub-Saharan Africa. So far, only $16 \%$ of LMIC countries are on track to achieve this goal, and none are on track in sub-Saharan Africa [7].

According to the 2006 national EPI survey in Ethiopia, only 50\% of the children were fully vaccinated, with wider variations from on region to another. These shows, half of the children were not fully protected [8]. In Ethiopian Demographic and Health Survey (EDHS), vaccination coverage increased from $14 \%$ in the 2000 to $20 \%$ in 2005 . The 2011 EDHS revealed that $24 \%$ of Ethiopian children in the age group of 12-23 months received all the recommended vaccines i.e. one dose each of BCG and measles, and three doses each of DPT and polio [9]. Therefore, the aim of this study was to assess the vaccination status and factors associated with it among children 12-23 months of age in Wadera District [10].

*Corresponding author: Solomon Berhanu, Department of Epidemiology, Jimma University, Ethiopia, Tel: 251932442238; E-mail: Solo.berhanu@gmail.com

Received April 24, 2018; Accepted June 11, 2018; Published June 18, 2018

Citation: Udessa G, Sena L Berhanu S (2018) Vaccination Status and Factors Associated With It among Children Aged 12-23 Months in Wadera District, South East Ethiopia. Health Care Current Reviews 6: 222. doi: 10.4172/23754273.1000222

Copyright: $\odot 2018$ Udessa G, et al. This is an open-access article distributed unde the terms of the Creative Commons Attribution License, which permits unrestricted use, distribution, and reproduction in any medium, provided the original author and source are credited. 


\section{Materials and Methods}

\section{Study area and population}

The study was conducted in Wadera District, capital of Guji zone of Oromia Regional state, Ethiopia, which is one of the 16 districts of the Zone. The district has one urban and 19 rural Kebeles. According to 2007 E.C Census projection, the district has a total population of 64,971 and 2261 children aged 12-23 months [11]. There were five Government health centers and 19 health posts providing EPI for the area. The source populations for the study were all children 12-23 months of age residing in the District [12].

\section{Study design and sample}

Cross-sectional study design was conducted from May-June 2016 among children 12-23 months of age that have Mothers/caretakers and residing in the district starting from pregnancy of the child up to the actual data collection of the current study in the area [13].

Single population proportion formula was used to calculate the minimum sample size for the study. With the assumption of proportion of fully vaccinated children aged between $12-23$ months was $22.9 \%$, $95 \%$ confidence interval, precision level of $5 \%, 10 \%$ non response rate and design effect of 1.5 [14]. The final sample size was 448 .

$$
\mathrm{n}=\underline{\mathrm{z}}_{\underline{\alpha / 2}} \underline{\underline{2}} \underline{\mathrm{p}(1-\mathrm{p})^{*}} \mathrm{DE}^{*} 10 \% \text { non response rate. }
$$$$
\mathrm{n}=\text { sample size }
$$

$Z=$ critical value of the Normal distribution at $\alpha / 2$

$$
\mathrm{p}=\text { sample proportion }
$$

$\mathrm{DE}=$ Non response rate

\section{Data collection}

Semi structured questionnaire was adapted from different literatures and interview administered technique with observation was done to collect data's from mothers/care takers [15]. Data on vaccination history was collected by observing immunization card and other data's were collected by interviewing mothers/caretakers. First, the questionnaire was developed in English and translated to the local language Afan Oromo. For checking the consistency, the Afan Oromo version were translated back to English by other language experts other than those who translate to Afan Oromo. Four nursing graduates, two Health Extension workers from Kebele's that were not included in the study and two supervisors were recruited for the data collection. A two-day intensive training were given before data collection on the data collection tools and ways of collecting data. For reliability and consistency the collected data, Pretest were done on 5\% of the total sample size one week priory to data collection on one of the Kebele that were not selected for the study. Amendment was made based on the results of the pre-test. Completeness of questionnaire was checked every day in the field by supervisors.

\section{Variables}

We defined fully vaccination status as; receiving all the basic childhood vaccinations recommended by WHO by the end of 24 months after birth. Vaccination status was considered fully vaccinated at 12 months, if the child had received the following vaccinations in the first year of life: One dose of BCG received shortly after birth, three doses of pentavalent, three doses of polio (excluding OPV-0 given shortly after birth), three doses of Pneumococcal Conjugated Vaccine (PCV) received at 6,10, and 14 weeks after birth respectively, Rotarix vaccine received at 6 and 10 weeks after birth and measles vaccinations at the age of 9 months. Fully vaccination coverage was determined for children who took all doses of the six vials (10 vaccines) and have immunization card [16].

\section{Socio demographic characteristics}

Age, marital status, religion, ethnicity, occupation, and educational status of mother/care taker, Family size, and Wealth index.

\section{Maternal and child health care services utilization}

Maternal TT vaccination status, ANC follow up, PNC follow up and knowledge and attitude of mothers/caretakers (about vaccine and vaccine preventable diseases).

\section{Child characteristics} born.

Sex of child, birth order, place of delivery, number of child ever

\section{Health facility related}

Presence of health facility, average walking time and supplies.

\section{Data analysis}

The collected data will be checked for its completeness manually, data cleaning and entry will be done using Epi-Data version 3.1. The entered data will be exported to SPSS version 21 for data analysis. Data editing, coding, checking and organization will done to transform the data into format suitable for farther analysis. Univariate analyses were done to assess vaccination status of children and Binary logistic regression was employed to assess the association between dependent and independent variables. Bivariate logistic regression were done to nominate variables for multivariate analysis with p-value less than or equal to 0.1. Multivariate logistic regression was done to calculate Adjusted Odds Ratio (AOR) with 95\% CI. To check variables having association with vaccination status, $\mathrm{p}$-value $<0.05$ level of significance and $95 \%$ confidence interval were used.

\section{Ethical considerations}

Ethical clearance for the study was obtained from Jimma University College of Public Health and communicated to administrative body of Wadera District. Data collection was under taken after getting permission from the District Health Office. Oral consent was also taken from every study participants before the actual data collection were started. Objectives of the study, their right to refuse and stop in between were explained for the every study participants.

\section{Results}

\section{Vaccination status}

From 448 study participants 440 mothers/caretakers were interviewed and give a response rate of $98.2 \%$. Out of the total 440 children's 182 (41.9\%) were fully vaccinated (Figure 1).

\section{Bivariate analysis result}

The Bivariate analysis shows that, 11 variables were nominated for multivariate analysis. From Socio demographic characteristics; educational status of mothers, educational status of fathers, and occupation of fathers (Table 1). From Maternal Health Care Utilization, availability and accessibility of Health Care and knowledge and attitude of mothers; number of ANC visits, Number of TT vaccine received by 
Citation: Udessa G, Sena L Berhanu S (2018) Vaccination Status and Factors Associated With It among Children Aged 12-23 Months in Wadera District, South East Ethiopia. Health Care Current Reviews 6: 222. doi: 10.4172/2375-4273.1000222

Page 3 of 5



Figure 1: Fully vaccination status of children $12-23$ months of age in Wadera district 2016

\begin{tabular}{|c|c|c|c|c|c|}
\hline \multirow[t]{2}{*}{ Variables } & \multirow[t]{2}{*}{ Categories } & \multicolumn{2}{|c|}{ Fully Vaccinated } & \multirow[t]{2}{*}{ COR(95\%CI) } & \multirow[t]{2}{*}{ P-Value } \\
\hline & & Yes (\%) & No (\%) & & \\
\hline \multirow{4}{*}{$\begin{array}{l}\text { Educational } \\
\text { status of mothers }\end{array}$} & Illiterate & $83(38.2)$ & 134(61.8) & 1 & \\
\hline & Read and Write & $27(41.5)$ & $38(58.5)$ & $1.1(0.9,5.5)$ & $0.05^{*}$ \\
\hline & Elementary & $55(42.0)$ & $76(58.0)$ & $1.2(0.9,6.0)$ & $0.06^{*}$ \\
\hline & $\begin{array}{l}\text { Secondary or } \\
\text { above }\end{array}$ & $17(63.0)$ & $10(37.0)$ & $2.7(1.2,6.3)$ & $0.02^{*}$ \\
\hline \multirow{3}{*}{ Age of Mothers } & $\leq 20$ & $13(44.8)$ & $16(55.2)$ & 1 & \\
\hline & $21-30$ & $123(42.6)$ & $166(57.4)$ & $0.9(0.5,1.3)$ & 0.36 \\
\hline & $>30$ & $46(37.7)$ & $76(62.3)$ & $0.7(0.3,1.7)$ & 0.48 \\
\hline \multirow{3}{*}{$\begin{array}{l}\text { Occupation of } \\
\text { mothers }\end{array}$} & Housewives & $140(40.1)$ & 209(59.9) & 1 & \\
\hline & Farmers & $13(35.1)$ & $24(64.9)$ & $2.1(0.9,5.1)$ & 0.8 \\
\hline & Others & $29(53.7)$ & $25(46.3)$ & $1.7(0.9,3.5)$ & 0.6 \\
\hline \multirow{4}{*}{$\begin{array}{l}\text { Educational level } \\
\text { of Father }\end{array}$} & Illiterate & $27(35.1)$ & $50(64.9)$ & 1 & \\
\hline & Read and Write & $42(45.2)$ & $51(54.8)$ & $1.5(1.2,3.9)$ & $0.01^{*}$ \\
\hline & Elementary & $75(40.1)$ & 112(59.9) & $1.2(0.9,3.4)$ & $0.11^{*}$ \\
\hline & $\begin{array}{l}\text { Secondary or } \\
\text { above }\end{array}$ & $33(58.9)$ & $23(41.1)$ & $2.7(1.3,5.4)$ & $0.01^{*}$ \\
\hline \multirow{3}{*}{$\begin{array}{l}\text { Occupation of } \\
\text { Father }\end{array}$} & Farmers & $177(39.7)$ & $178(60.3)$ & 1 & \\
\hline & Merchants & $21(43.8)$ & $27(56.2)$ & $1.9(1.1,3.2)$ & $0.02^{*}$ \\
\hline & Others & $39(55.7)$ & $31(44.3)$ & $1.6(0.8,3.4)$ & $0.20^{*}$ \\
\hline \multirow{2}{*}{$\begin{array}{l}\text { Number of family } \\
\text { size }\end{array}$} & $\leq 3$ & $22(40.0)$ & $33(60.0)$ & 1 & \\
\hline & $\geq 4$ & $160(41.6)$ & $225(58.4)$ & $1.1(0.6,1.9)$ & 0.8 \\
\hline \multirow{2}{*}{ Sex of the child } & Male & $93(46.8)$ & 132(58.7) & $1.0(0.7,1.5)$ & 0.99 \\
\hline & Female & $89(41.4)$ & $126(58.6)$ & 1 & \\
\hline \multirow{5}{*}{ Wealth Quintile } & Lowest & $46(35.4)$ & $84(64.6)$ & 1 & \\
\hline & Second & $19(40.4)$ & $28(59.6)$ & $1.2(0.6,2.0)$ & 0.75 \\
\hline & Middle & $36(41.4)$ & $51(58.6)$ & $1.3(0.7,2.3)$ & 0.44 \\
\hline & Fourth & $39(44.8)$ & $48(55.2)$ & $1.5(0.6,2.7)$ & 0.45 \\
\hline & Highest & $42(47.1)$ & $47(52.8)$ & $1.6(0.9,2.8)$ & 0.8 \\
\hline
\end{tabular}

N.B* $p<0.1$ and selected for multivariate analysis.

Table 1: Bivariate analysis of socio demographic characteristics among children aged 12-23 months in Wadera District, Guji Zone, June, 2016.

mothers, PNC follow up, place of delivery, knowledge of mothers/care takers towards vaccination, attitude of mothers/care takers towards vaccination, presence of health service and average walking time to reach vaccination services (Table 2 ).

\section{Multivariate analysis result}

The current study reveals that, there were 6 variables with significant

\begin{tabular}{|c|c|c|c|c|c|}
\hline \multirow{2}{*}{ Variables } & \multirow{2}{*}{ Categories } & \multicolumn{2}{|c|}{ Fully Vaccinated } & \multirow[t]{2}{*}{$\operatorname{COR}(95 \% \mathrm{Cl})$} & \multirow[t]{2}{*}{ P-Value } \\
\hline & & Yes & No & & \\
\hline \multirow{2}{*}{ № ANC Visit } & $\leq 2$ & $39(22.7)$ & 133(77.3) & 1 & \\
\hline & $\geq 3$ & $125(66.8)$ & $62(33.4)$ & $6.9(4.3,11.0)$ & $0.00^{*}$ \\
\hline \multirow{2}{*}{ № TT received } & $\leq 2$ & $109(37.6)$ & $181(62.4)$ & 1 & \\
\hline & $\geq 3$ & $58(77.3)$ & $17(22.7)$ & $5.7(3.1,10.2)$ & $0.00^{*}$ \\
\hline \multirow{2}{*}{ PNC } & Yes & $124(63.3)$ & $72(36.4)$ & $5.5(3.7,8.4)$ & $0.00^{*}$ \\
\hline & No & $58(23.8)$ & 186(76.2) & 1 & \\
\hline \multirow{2}{*}{$\begin{array}{l}\text { Place of } \\
\text { delivery }\end{array}$} & $\begin{array}{c}\text { Health } \\
\text { Institution }\end{array}$ & $86(63.2)$ & $80(36.8)$ & $3.7(2.4,5.7)$ & $0.00^{*}$ \\
\hline & Home & $96(31.6)$ & 208(68.4) & 1 & \\
\hline \multirow{2}{*}{$\begin{array}{l}\text { Presence of } \\
\text { health service }\end{array}$} & Yes & $177(42.7)$ & 238(57.3) & $2.9(1.1,8.1)$ & $0.03^{*}$ \\
\hline & No & $5(20.0)$ & $20(80.0)$ & 1 & \\
\hline \multirow{2}{*}{$\begin{array}{l}\text { Average } \\
\text { walking time } \\
\text { to reach } \\
\text { vaccination } \\
\text { services }\end{array}$} & $<30$ minutes & $171(45.1)$ & $208(54.9)$ & $3.7(1.9,7.4)$ & $0.00^{*}$ \\
\hline & $\geq 30$ minutes & $11(18.0)$ & $50(82.0)$ & 1 & \\
\hline \multirow{2}{*}{$\begin{array}{l}\text { Knowledge } \\
\text { of mother on } \\
\text { vaccination }\end{array}$} & Good & $158(57.70)$ & $116(42.3)$ & $8.6(5.2,14.3)$ & $0.00^{*}$ \\
\hline & Poor & $22(13.7)$ & $139(86.3)$ & 1 & \\
\hline \multirow{2}{*}{$\begin{array}{l}\text { Attitude toward } \\
\text { vaccination }\end{array}$} & Positive & $132(72.5)$ & $50(27.5)$ & $2.8(1.7,4.6)$ & $0.00^{*}$ \\
\hline & Negative & $48(19.0)$ & $205(81.0)$ & 1 & \\
\hline
\end{tabular}

N.B* $p<0.1$ and selected for multivariate analysis.

Table 2: Bivariate analysis of maternal health care utilization, availability and accessibility of Health Care and knowledge and attitude of mothers with children aged 12-23 months in Wadera District, Guji Zone, June, 2016.

association with the outcome variable. Mothers attended ANC three or above times were around four times $[\mathrm{AOR}=3.8(2.1-6.9)]$ more likely to fully vaccinate their child than mothers attended two or less. This study also identifies that mothers received three or above doses of TT vaccine were four times $[\mathrm{AOR}=4.0(1.7-9.6)]$ more likely to fully vaccinate their children as compared to mothers received two or less doses of TT vaccine. Children those born in health institution were almost two times $[\mathrm{AOR}=2.1(1.1-4.0)]$ more likely to be fully vaccinated than those who born at home. Mothers who had PNC follow up were almost three times $[\mathrm{AOR}=2.8$ (1.6-5.0)] more likely to fully vaccinate their children than those who didn't have. Children of mothers who walks less than 30 min to reach facilities to get the services were four times $[A O R=4.1(1.2-$ 13.2)] more likely to fully vaccinate their child than children of mothers who have to walk $30 \mathrm{~min}$ or longer. Children's whose mothers had good knowledge on vaccine and vaccine preventable diseases were around six times $[\mathrm{AOR}=5.7$ (2.9-11.2)] more likely to be fully vaccinated than children of mothers who had poor knowledge on vaccine (Table 3 ).

\section{Discussion}

According to this study, $41.9 \%$ children were fully vaccinated and $5.9 \%$ were totally unvaccinated. This might be due to many factors that have the potential for interference of mother to get fully vaccinate their children, and the possible once might be BCG and Measles vaccine vials, which 20 and 10 doses per vial respectively, if the number of children were not enough to open the vials, most of the time the service providers didn't open the vials and give the vaccine for the children's at that moment. This is because, one of the way of reducing wastage rate of vaccines is to wait or appoint reasonable number of children's to open the vials and be effective with respect to using the vaccines properly. The actions they take to manage vaccine wastage rate then affects children's to be fully vaccinate [17-22].

Mothers attended ANC three or above times were around four 
Citation: Udessa G, Sena L Berhanu S (2018) Vaccination Status and Factors Associated With It among Children Aged 12-23 Months in Wadera District, South East Ethiopia. Health Care Current Reviews 6: 222. doi: 10.4172/2375-4273.1000222

Page 4 of 5

\begin{tabular}{|c|c|c|c|c|c|}
\hline \multirow{2}{*}{$\begin{array}{l}\text { Variables } \\
\text { Educational status of } \\
\text { mothers }\end{array}$} & \multirow[t]{2}{*}{ Categories } & \multicolumn{2}{|c|}{ Fully Vaccinated } & \multicolumn{2}{|c|}{ Odd Ratio(95\%Cl) } \\
\hline & & Yes & No & COR & AOR \\
\hline & Illiterate & $83(38.2$ & $134(61.8)$ & 1 & 1 \\
\hline & Read and Write & $27(41.5)$ & $38(58.5)$ & $1.1(0.9,5.5)$ & $1.2(0.3,4.6)$ \\
\hline & Elementary & $55(42.0)$ & $76(58.0)$ & $1.2(0.9,6.0)$ & $0.9(0.2,4.1)$ \\
\hline & Secondary or above & $17(63.0)$ & $10(37.0)$ & $2.7(1.2,6.3)$ & $0.6(1.1,2.8)$ \\
\hline \multirow{4}{*}{$\begin{array}{l}\text { Educational level of } \\
\text { Father }\end{array}$} & Illiterate & $27(35.1)$ & $50(64.9)$ & 1 & 1 \\
\hline & Read and Write & $42(45.2)$ & $51(54.8)$ & $1.5(1.2,3.9)$ & $1.7(0.7,4.2)$ \\
\hline & Elementary & $75(40.1)$ & $112(59.9)$ & $1.2(0.9,3.4)$ & $2.9(1.03,8.4)$ \\
\hline & Secondary or above & $33(58.9)$ & 23(41.1) & $2.7(1.3,5.4)$ & $2.5(0.7,8.2)$ \\
\hline \multirow{3}{*}{ Occupation of Father } & Farmer & $177(39.7)$ & $178(60.3)$ & 1 & 1 \\
\hline & Merchant & $21(43.8)$ & $27(56.2)$ & $1.6(0.8,3.4)$ & $2.9(1.01,8.1)$ \\
\hline & Others & $39(55.7)$ & $31(44.3)$ & $1.9(1.1,3.2)$ & $2.3(1.03,5.0)$ \\
\hline \multirow{2}{*}{ № ANC Visit } & $\leq 2$ & $39(22.7)$ & 133(77.3) & 1 & 1 \\
\hline & $\geq 3$ & $125(66.8)$ & $62(33.4)$ & $6.9(4.3,11.0)$ & $3.8(2.1,6.9)^{*}$ \\
\hline \multirow{2}{*}{ № TT received } & $\leq 2$ & 109(37.6) & $181(62.4)$ & 1 & 1 \\
\hline & $\geq 3$ & $58(77.3)$ & $17(22.7)$ & $5.7(3.1,10.2)$ & $4(1.7,9.6)^{*}$ \\
\hline \multirow{2}{*}{ PNC } & Yes & $124(63.3)$ & $72(36.4)$ & $5.5(3.7,8.4)$ & $2.8(1.6,5.0)^{*}$ \\
\hline & No & $58(23.8)$ & $186(76.2)$ & 1 & 1 \\
\hline \multirow{2}{*}{ Place of delivery } & Health Institution & $86(63.2)$ & $80(36.8)$ & $3.7(2.4,5.7)$ & $2.1(1.1,4.0)^{*}$ \\
\hline & Home & $96(31.6)$ & $208(68.4)$ & 1 & 1 \\
\hline \multirow{2}{*}{$\begin{array}{l}\text { Knowledge of mother on } \\
\text { vaccination and VPD }\end{array}$} & Good & $158(57.70)$ & $116(42.3)$ & $8.6(5.2,14.3)$ & $5.7(2.9,11.2)^{\star}$ \\
\hline & Poor & $22(13.7)$ & 139(86.3) & 1 & 1 \\
\hline \multirow{2}{*}{$\begin{array}{l}\text { Attitude toward } \\
\text { vaccination }\end{array}$} & Positive & $132(72.5)$ & $50(27.5)$ & $2.8(1.7,4.6)$ & $1.5(0.7,3.0)$ \\
\hline & Negative & $48(19.0)$ & $205(81.0)$ & 1 & 1 \\
\hline \multirow{2}{*}{ Presence of health service } & Yes & $177(42.7)$ & $238(57.3)$ & $2.9(1.1,8.1)$ & $0.4(0.04,3.8)$ \\
\hline & No & $5(20.0)$ & $20(80.0)$ & 1 & 1 \\
\hline \multirow{2}{*}{$\begin{array}{l}\text { Average walking time to } \\
\text { reach vaccination services }\end{array}$} & $<30$ minutes & $171(45.1)$ & $208(54.9)$ & $3.7(1.9,7.4)$ & $4.1(1.2,13.2)^{*}$ \\
\hline & $\geq 30$ minutes & $11(18)$ & $50(82.0)$ & 1 & 1 \\
\hline
\end{tabular}

$\mathrm{NB}^{*}$ statistically significant at $\mathrm{p}$ value less than 0.05 and $95 \% \mathrm{Cl}$.

Table 3: Multivariate logistic regression on fully vaccination status of children 12-23 months of age and associated factors in Wadera district 2016.

times $[\mathrm{AOR}=3.8(2.1-6.9)]$ more likely to fully vaccinate their children than mothers attended two or less. This is consistence with study done in Ambo and Bangladesh [10,23]. The reason might be, Mothers who repeatedly attend ANC gets more information related to vaccination and the information they get during their repeated ANC follow up might help them to develop good attitude towards vaccination of children's, which leads them to fully vaccinate their children. The other reason why they fully vaccinate their children might be, during their repeated ANC follow up they get the chance of observing other mothers who were committed to vaccinate their children and that might lead them to do vaccinate their children too.

This study also identifies that, mothers received three or above doses of TT vaccine were four times $[\mathrm{AOR}=4.0(1.7-9.6)]$ more likely to fully vaccinate their children than mothers received two or less doses of TT vaccine and the finding is also consistence with study done in Ambo and Bangladesh [10,23]. This might be explained by; mothers who got three and more dose of TT might have better knowledge and attitude on vaccination and have good commitment to getting vaccinated their child based on the schedule. The repeated health facility visit for getting TT vaccine might help them to get vaccination related information and knowledge. In addition, looking mothers who got three and more TT vaccine can imply that, they have good attitude and practice on vaccination and which might led them to fully vaccinate their children too.

Those children's born in health institution were almost two times $[\mathrm{AOR}=2.1(1.1-4.0)]$ more likely to be fully vaccinated than those who born at home; which is consistent with studies done Ambo District, Jigjiga District and Mozambique [10,20,22]. This can be explained by; being delivered at health facility, in addition to having safe delivery by health professionals, had additional benefit on post-delivery follow up and vaccination related information from health professionals. The information includes appointing the mother for vaccination and other maternal and child health, which might increase the practice of mother to fully vaccinate their children.

Mothers who had PNC follow up were almost three times [AOR=2.8 (1.6-5.0)] more likely to fully vaccinate their children than those who didn't have, and this finding is similar with study done in Wonago District [21]. The possible reason might be; vaccination of children is one of the components of PNC follow up and which might lead mothers to fully vaccinate their children. The information and education they get during PNC follow up from health professionals might also increase mother practice to fully vaccinate their children.

Children whose mothers had good knowledge on vaccine and vaccine preventable diseases were around six times $[\mathrm{AOR}=5.7$ (2.911.2)] more likely to be fully vaccinated than children of mothers who had poor knowledge on vaccine and VPD; and the finding is similar with study done in Sinana District and Oromia Regional state $[11,14]$. This strong association can be explained by; fully vaccinating of children is practice and one of the determining factors for good practice is having knowledge, having good knowledge towards vaccination and VPD can increase the practice of fully vaccinating children. Knowledge 
Citation: Udessa G, Sena L Berhanu S (2018) Vaccination Status and Factors Associated With It among Children Aged 12-23 Months in Wadera District, South East Ethiopia. Health Care Current Reviews 6: 222. doi: 10.4172/2375-4273.1000222

towards vaccination and VPD can also increase the fear that missing unvaccinated can put children's health at risk of different diseases, so that due to this fear mothers may triggered to fully vaccinate their children [23-26].

The other factor that the study revealed is distance of home to area for vaccination service. Children of mothers who walked less than $30 \mathrm{~min}$ to reach to the facilities were four times $[\mathrm{AOR}=4.1(1.2-13.2)]$ times likely to be fully vaccinated than children of mothers who have to walk $30 \mathrm{~min}$ or longer; and the finding is consistence with study done in Sudan [27]. This might be due to fear of or being boredom of walking more than $30 \mathrm{~min}$ to reach to the facility by the care givers/mothers. As the traveling time to reach facilities increaser's different problems might also be increases like, risk of getting different types of incidents, there might be no one at home and the home might be at risk of different incidents, there might be other children in home and there may be no one to look at them. Especially in the setting of rural part of Africa, there might be an increased risk for women's to travel more distance alone [28].

\section{Conclusion}

The current study reveals that, fully vaccination coverage of Children's 12-23 months of age is low. And a total of six Factors associated with fully vaccination status were identified by the study. Those mothers with three and more ANC follow, received three or more TT doses, utilizes PNC service, who delivers their child at Health facility, with good knowledge on vaccination and who uses less than 30 min of average walking time to reach vaccination services were have positive association with fully vaccination.

\section{Acknowledgement}

The researchers would like to thank Wadera District Health Office for their permission, support and for providing us the necessary information to carry out the study in the District. And also our thanks go to all the study participants, data collectors and supervisor for their commitment and full cooperation during data collection. Finally we would like to thank Jimma University and Guji Zone Health Department for their support on material and free internet service during literature collection.

\section{References}

1. I10k.jsi.com.

2. WHO (2009) State of the world's vaccines and immunization.

3. Federal Ministry of Health (2015) Ethiopia national expanded programme on immunization.

4. Immunization summary 2013

5. WHO (1974) Handbook of resolutions: World health assembly, Fourteenth plenary meeting.

6. WHO (2007) Children and the millennium development goals progress towards a world fit for children.

7. Oyo-Ita A, Nwachukwu CE, Oringanje C, Meremikwu MM (2011) Interventions for improving coverage of child immunization in low- and middle-income countries. Cochrane Database Syst Rev.
8. Kidane T, Yigzaw A, Sahilemariam Y, Bulto T, Mengistu H, et al. (2008) National EPI coverage survey report in Ethiopia, 2006. J of Health Development 22:148157.

9. Ethiopia Demographic and health survey (2012)

10. Belachew Etana (2012) Factors Affecting immunization status of children aged 12-23 Months in Ambo Woreda, Central Ethiopia BMC Public Health 12: 566

11. Legesse E, Dechasa W (2015) An assessment of child immunization coverage and its determinants in Sinana District, Southeast Ethiopia: BMC pediatr 15: 31

12. WHO (2008) Reaching Every District Approach: A Guide for District Health Management Teams.

13. Glauber JH (2003) The immunization delivery effectiveness assessment score: a better immunization measure? Pediatrics 112: e39-45.

14. Hussen M, Alemayehu A (2013) Assessment of child immunization coverage and associated factors in oromia regional state, Eastern Ethiopia.

15. Guji zone health deparment. Compiled Guji Zone Surveillance 2014/2015

16. WHO Global Immunization Vision and Strategy 2006-2015.

17. Baamer AA (2010) Coverage of and barriers to routine child vaccination in Mukalla district, Hadramout governorate, Yemen. East Mediterr Health J 16: 223-227.

18. Juliet N, Babirye, Ingunn MS. Engebretsen, Makumbi F, et al. (2012) Timeliness of childhood vaccinations in kampala uganda: A Community-Based CrossSectional Study. PLoS ONE 7: e35432.

19. Federal Democratic Republic of Ethiopia Ministry of Health: Ethiopian annual health performance report of HSDP-III. EFY2001 (2008/2009) (2009).

20. Abdi Nur M, Amsalu F, Walelegn W, Manay K (2014) Immunization coverage of 12-23 months old children and associated factors in Jigjiga District, Somali National Regional State, Ethiopia 14: 865

21. Tadesse H, Deribew A, Woldie M (2009) Predictors of defaulting from completion of child immunization in south Ethiopia, May 2008-A case control study. BMC Public Health 9: 150.

22. Jagrati $\bigvee$ Jani, De Schacht C, llesh V Jani, Bjune G (2008) Risk factors for incomplete vaccination and missed opportunity for immunization in rural Mozambique. BMC Public Health 8: 161.

23. Andrews-Chavez J, Biswas A, Gifford M, Eriksson C, Dalal K (2012) Identifying households with low immunization completion in Bangladesh 4: 1088-1097.

24. Sebahat D Torun, Nadi Bakırc (2006) Vaccination coverage and reasons for non-vaccination in a district of Istanbul. BMC Public Health 6: 125

25. Rup KP, Manash PB, Jagadish M (2008) Factors associated with immunization coverage of children in Assam, India: Over the first year of life. J Trop Pediatr 52: $249-252$

26. Mosiur R, Sarker ON (2010) Factors affecting acceptance of complete immunization coverage of children under five years in rural Bangladesh. Salud Publica Mex 52: 134-140.

27. Ibnouf A, Van den Borne $\mathrm{H}$, Maarse $\mathrm{J}$ (2007) Factors influencing immunisation coverage among children under five years of age in Khartoum State, Sudan. SA Fam Pract 49: 14-14f.

28. Mapatano MA, Kayembe K, Piripiri L, Nyandwe K (2008) Immunisation-related knowledge, attitudes and practices of mothers in Kinshasa, Democratic Republic of the Congo SA Fam Pract 50: 61-61e. 